\title{
FAREWELL TO HAARLEM
}

On a broad curve of the Spaarne Canal in Haarlem, tightly hemmed in by its neighbours, stands a graceful old house - No. 46 Spaarne - IUGS operational headquarters for the last eight years. Here, from the large windows of the Union's second floor offices, one can enjoy a multitude of ever-changing scenes comprising bicycles, bridges, cars, barges - all on a backdrop of the stately Geological Survey of The Netherlands which faces the Haarlem Secretariat.

It was in 1968 that Dr. Simon van der Heide succeeded the late Professor van Leckwijck as Secretary General of the Union. The transfer of the Secretariat from Antwerp to Haarlem was completed by May and since that time Dr. van der Heide has carried out his responsibilities with quiet competence, ably supported by his assistant Mar jo Peltenburg-Jager.

Dr. van der Heide's term of office has witnessed several

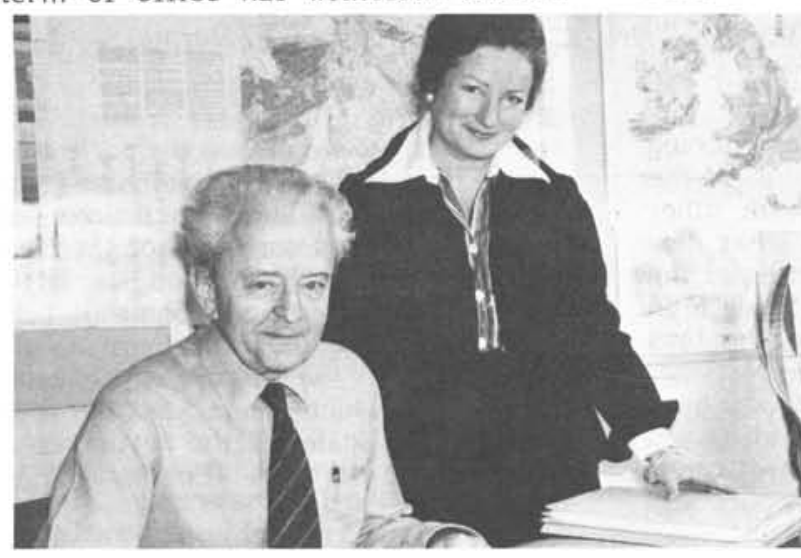

major landmarks in the history of the IUGS such as the implementation of the International Geological Correlation Program and the establishment of the Inter-Union Commission on Geodynamics. His calm dedication and helpful counsel have been appreciated by everyone who has had the opportunity to work with him, and especially by the many project leaders who have welcomed his patient advice while operating from some isolated outpost in a far corner of the world.

In taking stock of the responsibilities, tasks and challenges that lie ahead for me and my staff in Ottawa, I have been filled with admiration for Dr. van der Heide's achievements. I have been moved as well by his and Marjo PeltenburgJager's unflagging co-operation and assistance. It is therefore with great personal pleasure that I take this opportunity to thank them both, and to congratulate them on a job well done.

Simon van der Heide and Marjo Peltenburg-Jager at work in the Haarlem Secretariat. (Photo: Courtesy GSC, 21-78) 